\title{
Universal Health Coverage - Inclusion of TB in National Health Insurance Programs and Recommendations for Expansion of Coverage of TB Services in LMICs
}

\author{
Hala Jassim AlMossawi ${ }^{1}$, Neeraj Kak ${ }^{1 *}$, Yogan Pillay ${ }^{2}$, Refiloe Matji', Sharanya Joshi' \\ 'Center for Innovations and Technology, University Research Co., LLC, Chevy Chase, MD, USA \\ ${ }^{2}$ National Department of Health, Pretoria, South Africa
}

Article Info

\section{Article Notes}

Received: August 05, 2018

Accepted: August 22, 2019

\section{*Correspondence:}

Dr. Neeraj Kak, University Research Co., LLC (URC), Chevy Chase, MD, USA; Email: nkak@urc-chs.com.

(c) $2019 \mathrm{KakN}$. This article is distributed under the terms of the Creative Commons Attribution 4.0 International License.

\section{Keywords:}

Universal Health Coverage

National Health Insurance

Tuberculosis

Quality Care

Incentives
Abstract

Background: Increasingly lower- and middle-income countries have moved towards the adoption of National Health Insurance (NHI) models as a means to support sustainable financing for Universal Health Care. National Health Insurance in the form of government-led, publicly supported and/or centrally managed insurance programs in various forms have been introduced in countries such as Brazil, Cambodia, China, Rwanda, Mexico, South Africa, and Thailand and have demonstrated important successes. The impact of these insurance programs on the use of tuberculosis (TB) services and outcomes is unclear.

Objectives: This assessment examines how TB is included (or neglected) in the service delivery package in $\mathrm{NHI}$ programs and how effectively $\mathrm{NHI}$ programs interact with National TB Programs (NTP) and other TB control stakeholders to plan, implement, and measure TB service use. This assessment aims to analyze the extent to which several NHI programs currently in place or in development in high-burden TB countries have integrated TB services. It synthesizes the findings of assessments in four countries - Thailand, Peru, Philippines, and India - which have adopted publicly supported health insurance programs.

Results: The four case studies demonstrate that the integration of TB services with national health insurance can have a positive effect on access to services and their quality. On the other hand, each of the models assessed impose different types of restrictions which can limit the utilization of services. Some restrictions are planned and are part of the design of the insurance model. Others, however, are indirect or unintended consequences of implementation. As it relates to TB, the findings of the assessment have highlighted the need to carefully examine the impact of restrictions in terms of access and use of TB services. In Thailand, the case study found that long wait times at facilities discouraged patients from obtaining services through national health insurance. In the Philippines, the case study found that many patients perceive that they will have to pay direct and indirect costs for TB services in the public sector and prefer instead to seek treatment in the private sector, including pharmacies, to reduce costs. The primary goal of publiclysupported health insurance programs is to improve access to care for a vulnerable segment of the population and, especially as it relates to TB, have the potential to play an important role in improving public health. However, specific objectives for health insurance programs are not typically defined in terms of disease objectives. In countries with significant burdens of key diseases like TB which threaten to jeopardize overall population health (as well as long term growth and development), specific considerations should be made to ensure that the $\mathrm{NHI}$ program is designed to be a driving force for controlling the epidemic. The decision to develop and adopt a publicly-supported insurance model should ideally form part of broader health systems reform efforts, and the design of the insurance model should, therefore, include features geared at reinforcing and advancing the country's health systems strengthening objectives. An issue facing each country, in different degrees, is the separation between the functions of the NTP and the insurance planning and implementation agency. The addition of an insurance program, and possibly other agencies with financing or regulatory functions, adds another level of complexity in terms of planning, organizing, and delivering health services.

Conclusion: A key overarching conclusion from the assessment is that strong coordination is needed between health policymakers and program managers to carefully design models for integration of TB services under national health insurance. Careful planning is needed to ensure that all parties understand their roles and responsibilities within the systems and that health providers are motivated to provide high-quality TB services, and patients have incentives to utilize the services. 


\section{Introduction}

Universal Health Coverage (UHC), defined by the World Health Organization as "access to key promotive, preventive, curative and rehabilitative health interventions for all at an affordable cost, thereby achieving equity in access" ${ }^{11}$ has increasingly been adopted as a health systems goal in low- and middle-income countries (LMIC). This definition of UHC is designed to capture the principals of equity of access to health services, provision of quality care, and financial risk pooling, and in recent years many developing countries have moved to incorporate UHC as a component of health system reform. Efforts to reduce the financial burden associated with poor health and reduce the reliance on direct payments from patients for health services and commodities (which have the potential to inflict severe economic hardship and may deter patients from seeking care) have led countries to explore the development of prepayment and risk pooling mechanisms. Several mechanisms exist for countries to encourage risk pooling and reduce direct health payments, including out of pocket payments, targeted taxes and levies ${ }^{2}$, and increasingly LMICs have moved towards the adoption of National Health Insurance (NHI) models as a means to support sustainable financing for UHC. A landscape analysis conducted by UNICEF found that almost all LMIC in Asia and Africa have adopted formal UHC policies and that health insurance programs form a critical part of the social protection measures developed to attain UHC objectives ${ }^{3}$. National Health Insurance in the form of government-led, publicly supported and/or centrally managed insurance programs come in various forms in different countries and are often combined with other forms of social protection programming. Health financing strategies designed to ensure coverage for all, with an emphasis on the very poor or marginalized, have been introduced in countries such as Brazil, Cambodia, China, Rwanda, Mexico, South Africa, and Thailand and have demonstrated important successes.

The impact of these insurance programs on use of tuberculosis (TB) services and outcomes is unclear. The different NHI programs currently in place or in development in high-burden TB countries include a varying degree of integration of TB services. There is a need to explore how the use of these mechanisms can increase universal coverage for TB patients in both low- and high-burden countries. As TB is a critical public health threat in many countries, the inclusion of services for TB diagnosis, treatment, and follow-up care within NHI programs has the potential to play an important role in extending care to TB patients not currently reached. There is also a need to ensure that health care providers operating under UHC/NHI models have the funding available to provide TB awareness among communities and TB education to patients in high-burden TB countries. At the same time, as TB is a highly infectious airborne disease and TB control should be considered a public good, it is important to examine what gaps exist in the design of insurance programs as it relates to the attainment of TB control objectives (for example regarding active case finding or community-based care).

There is little information or consensus on how best to integrate TB into national health insurance programs. A stronger understanding of how TB services are delivered under NHI programs is critical for ensuring coordinated planning and expansion of critical TB services, particularly multi-drug resistance TB (MDR-TB) services.

Additionally, in TB high-burden and developing countries, there is very little information on how explicit inclusion of TB services within an NHI program impacts early case detection, TB treatment success, control or universal access to basic directly observed treatment, short-course (DOTS). Increasing access and coverage to TB services was not often an explicit focus of the NHI schemes from the literature reviewed. The general trend from the literature indicates that coverage of TB under national insurance leads to a positive impact and increased patient access to TB services (although data is more widely available for developed rather than TB high-burden countries). However, a few studies have pointed to the possibility of insurance procedural delays leading to delays in the diagnosis or treatment of TB. A number of reasons can explain the limited information on the impact of including TB treatment modalities under NHI. Firstly, in most highburden countries, basic TB treatment (i.e., first-line drugs for drug-sensitive TB and drugs for retreatment cases) have been traditionally provided free of charge under National TB Programs and may continue to be provided alongside NHI programs. Secondly, as NHI programs are frequently administered by agencies which are overseen by the Ministry of Finance or other regulating agencies, there may not be a history of analyzing disease-specific outcomes of members, depending on the degree of coordination or joint planning which occurs with the Ministry of Health. Thirdly, the development of NHI programs in some countries may occur alongside shifts to decentralize the NTP, which can result in gaps in the capacity to conduct strategic planning, data collection, and program evaluation.

Although many LMIC countries have adopted the principals of UHC, most still have a long way to go to ensure that UHC is achieved based on the definition outlined above (equitable access to key health services for all at an affordable cost). Figure 1 below draws from a 2010 WHO Health Systems Financing report and details the hypothetical, but plausible, status of a country which has adopted a UHC framework but falls short of providing routine, accessible, and high-quality health care to all who need $i^{2}$. Depending on the country, the approach to prepayment or risk-pooling to provide funding for health service delivery may include taxes (wage, income, or other), 


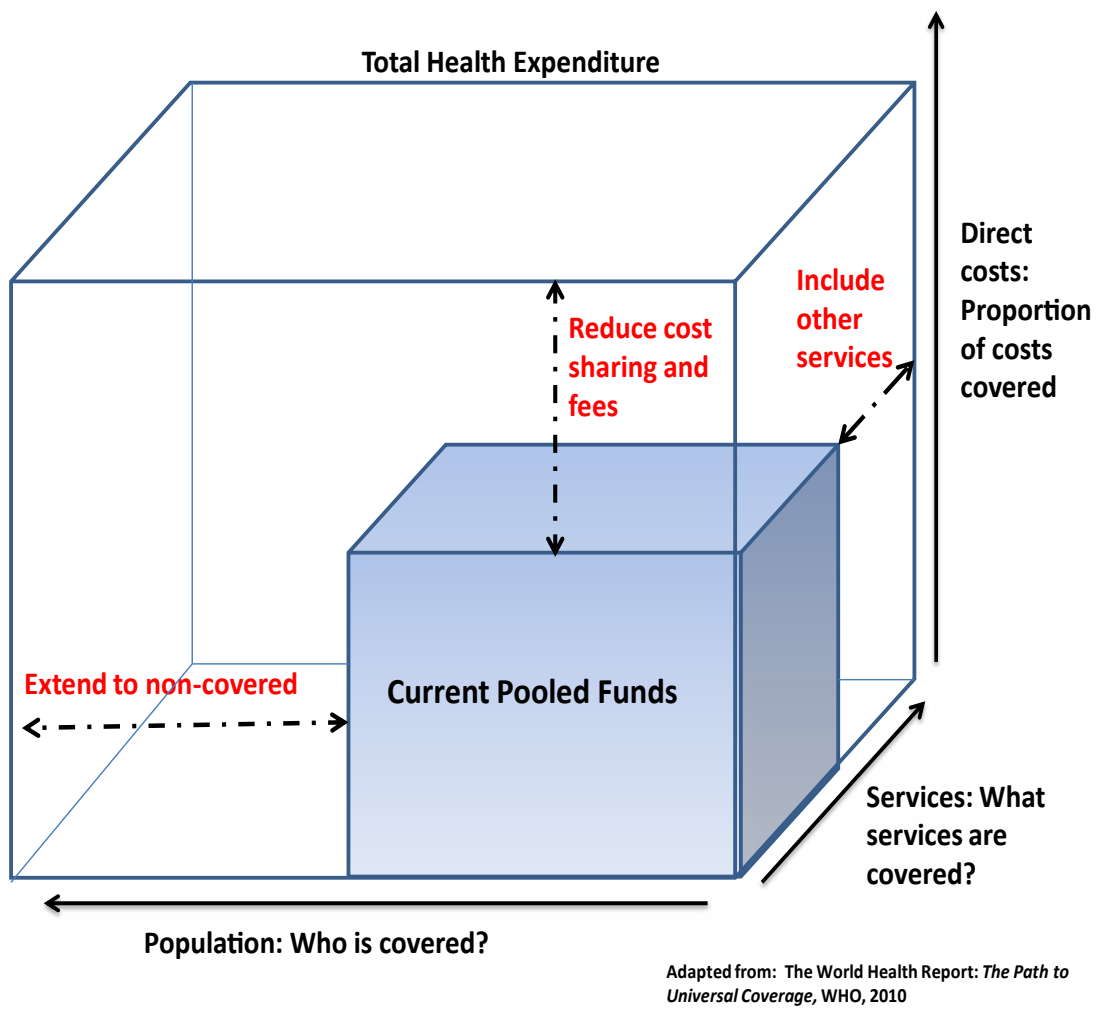

Figure 1: Dimensions of Universal Health CoverageAdapted.

levies, or insurance premiums. For the country described in the figure, the available funding pool covers only a portion of the population for only a portion of services, requiring a higher degree of "cost sharing" from the patient in the form of direct or out-of-pocket payments for health services or commodities. An increase in direct costs can be expected to affect a patient's willingness to access health services, as it may require trade-offs with other needs (housing, food, etc.). In the case of suspected TB, a high direct cost for services may encourage patients to delay seeking care or "shop around" for less expensive treatment from alternative (potentially unqualified) providers, which poses the risk of continued transmission in the community.

In countries which have adopted an NHI program, in an ideal setting, members should be expected to benefit from comprehensive, easy-to-use, and widely accessible coverage for all internationally recommended levels of TB prevention, care, and treatment. In the example in Figure 1, where only a portion of necessary services are covered, a patient may be required to routinely seek outside services to fill gaps in coverage. The extent to which necessary TB services are included within the package of insurance benefits will also affect whether a patient is able to utilize the insurance program to cover all aspects of care or is required to use other providers for certain services, which may result in delays or potential loss in follow-up as the non-covered services increase the direct costs to the patients. In a high-burden TB country, ensuring routine coverage for TB services for all patients, especially poorer patients who are more vulnerable to increases in direct costs, should be a priority objective for UHC programs.

Another method for evaluating the effectiveness of a UHC program, described in Figure 2a, addresses questions of coverage (i.e., what services are included in the coverage package, and what population is covered by the program), access, use (what barriers do patients experience when accessing coverage and utilizing services), and quality of services (do in-service providers have capacity to deliver all services in the coverage package and is service quality assured?). For universal coverage to make a real impact on improving health outcomes, it is necessary to integrate a focus on health systems elements related to access and quality of services to ensure that any additional health system requirements generated by the incorporation of an NHI program are met. For example, if the registration process for NHI membership is difficult to navigate or not well understood by patients, uptake may be low as patients opt for direct pay-for-service providers. The NHI schemes and/or MOHs in high-burden countries may also be required to set aside resources for community and patient education to prevent new infections.

If this framework is applied to TB services covered within NHI programs (Figure $2 \mathrm{~b}$ ), it is possible to analyze the impact of the program on the improvement of TB outcomes. In terms of routinely increasing the numbers 


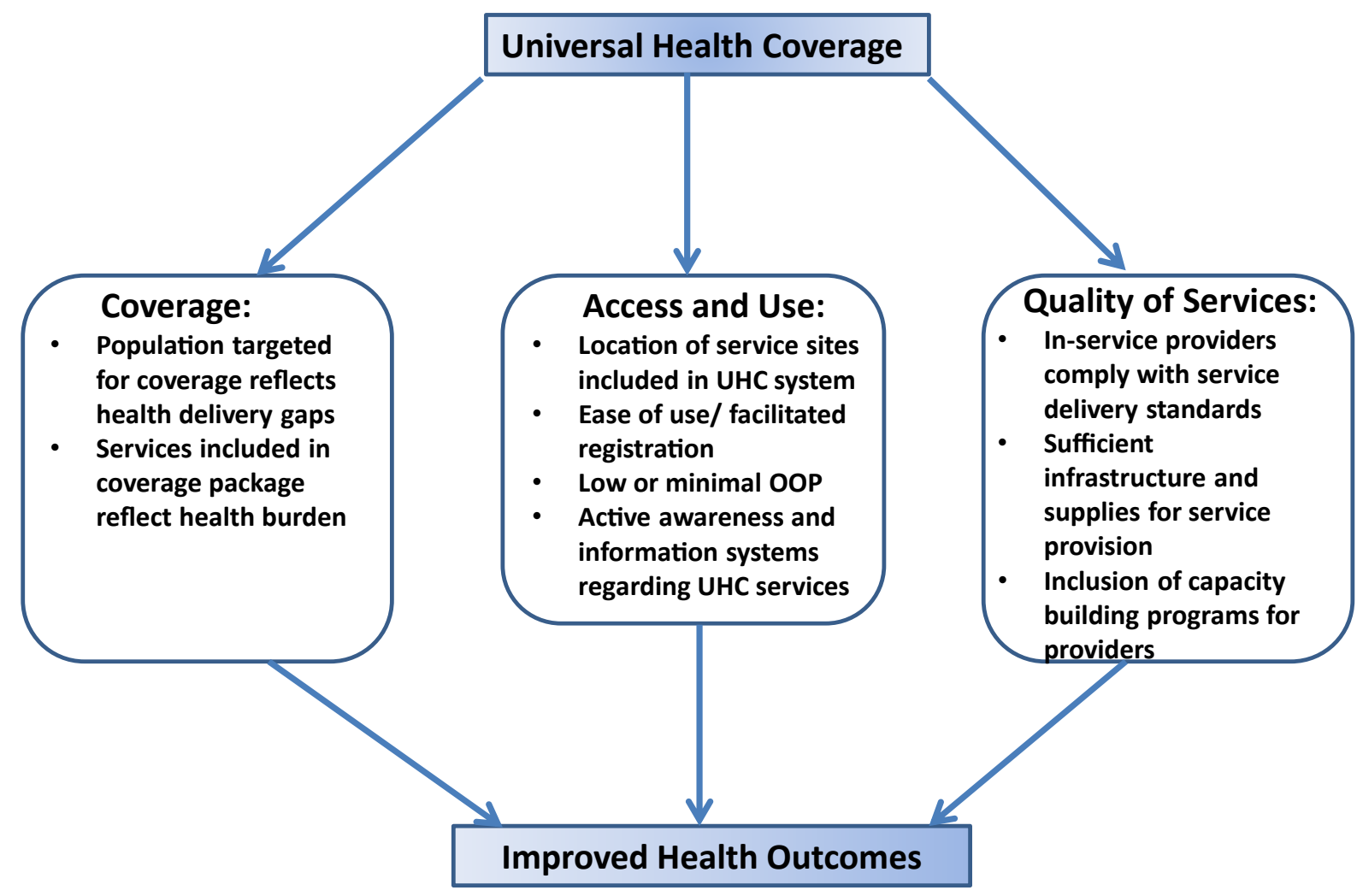

Figure 2a: Framework for Evaluating UHC Systems.

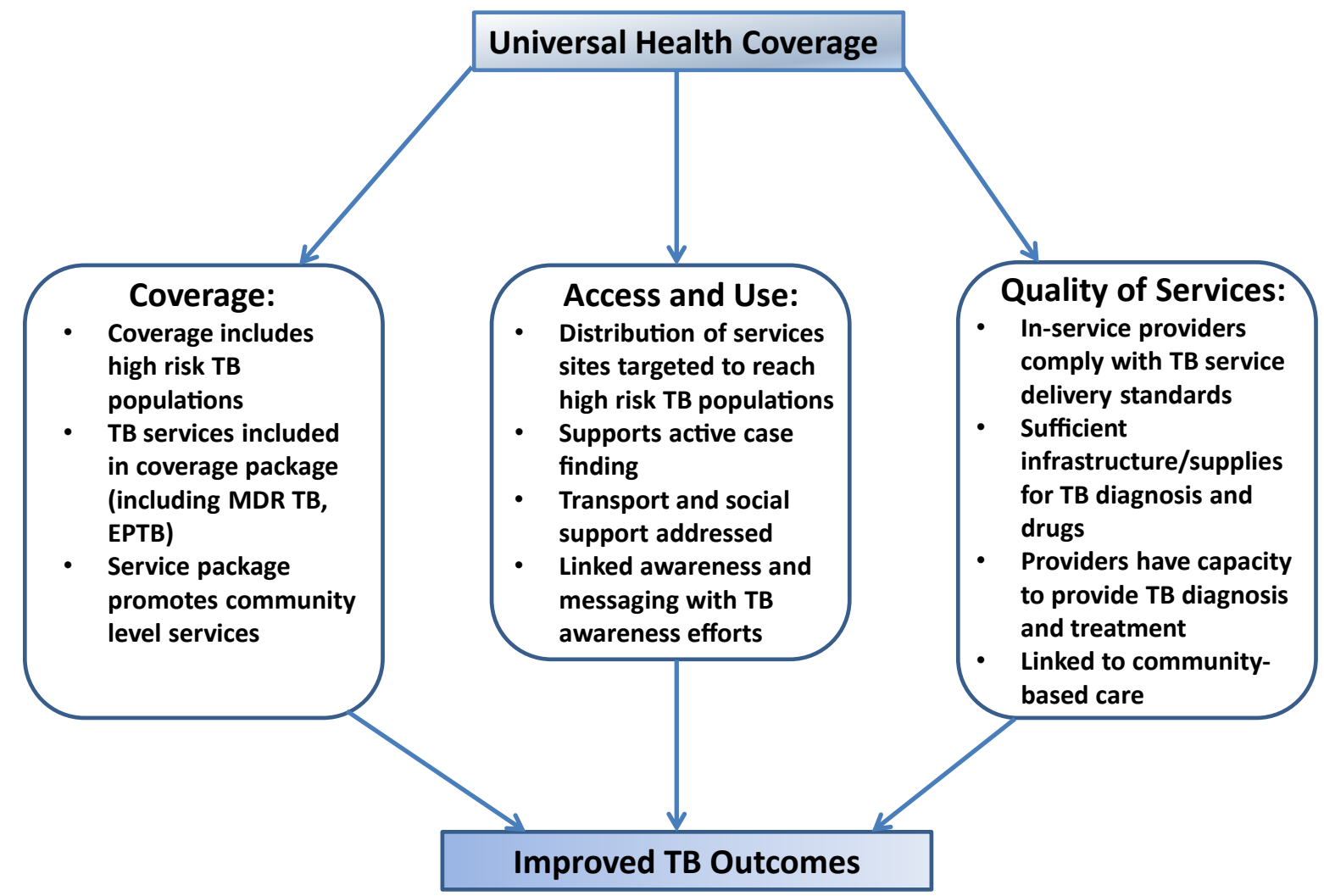

Figure 2b: Framework for Evaluating TB Services within UHC Systems. 
of patients benefitting from high-quality TB services, it is important to examine how the population targeted for coverage under the health insurance program overlaps with the populations with traditionally low TB service use and identify where the gaps are. Similarly, it is important to examine what TB services from Box 1 are included in the package of services covered by the insurance program and what services the patient is obliged to seek from another source (for example, if MDR-TB services are not included, or certain diagnostics). As discussed above, in an ideal setting a patient should be able to receive all components of TB care by accessing the insurance program, without needing to "shop around" to fill gaps in service requirements. Access to and use of the insurance program poses critical questions for TB patients, especially as TB is a public health threat and the need to actively identify TB cases is critical to improving TB control overall. In this sense, it is important to evaluate whether the insurance program is also able to contribute to the active enrollment of populations at risk of TB, to encourage more TB patients to access treatment. Similarly, the location of in-service TB providers is an important factor affecting whether patients will access and use services. Restrictions regarding where patients can seek TB care, long distances to service sites, and lack of transport support can reduce adherence to treatment and encourage patients to default or seek more convenient direct-pay service options. Finally, the quality of TB care provided by in-service providers is an important consideration. For this, it is important to evaluate the extent to which in-service providers are able to meet TB service delivery standards, what types of provider capacity building programs are used by the insurance program (for example, are there refresher training requirements linked to provider or facility accreditation) as well as how well facility-based services are able to link with communitybased TB care providers, if present.

\section{Objectives}

The objective of this assessment is to examine the extent to which TB has been integrated into NHI programs in several high-burden TB countries and to analyze the impact of NHI on the achievement of National TB Control objectives. This report synthesizes the findings of assessments in four countries - Thailand, Peru, Philippines, and India - which have adopted publicly supported health insurance programs in order to:

- Examine the extent to which TB services have been integrated within NHI schemes

- Examine the roles of TB stakeholders within the design and implementation of NHI programs

- Outline gaps and recommendations for improved delivery of TB services within NHI models
This assessment should be considered as a starting off point for understanding the role of NHI programs in meeting TB control objectives. Additional future work will be needed to assist NTP and NHI program managers in highburden countries to frame objectives and implement plans for future inclusion and/or expansion of TB prevention and care coverage in schemes. Additionally, this report should assist in creating a knowledge base and recommendations which program managers can use when planning for the design and implementation of NHI programs in other TB high-burden countries.

\section{Methodology}

In each of the four countries, data collection teams conducted desk reviews as well as on-site visits to TB treatment facilities and semi-structured interviews with government program managers and stakeholders. The methodology utilized for the assessments is described in a general form below, which was modified slightly in each country to accommodate differences in the insurance programs targeted.

Based on a preliminary analysis of the existing information on TB services within NHI programs, the interview guides for the country-level assessments were organized around the following broad information areas:

- What are the characteristics of the NHI model and who are principal beneficiaries?

- What are the implications of NHI for TB control programs, inputs, services?

- What are the additional health system requirements generated by NHI in terms of human resources, infrastructure and equipment/ supplies, and capacity building (both clinical and managerial) for TB services under the health insurance model?

- What are the implications of NHI for the communities most affected by TB, and for TB patients in terms of awareness, access, and quality of care?

- What are the current programs underway to improve health service delivery, and how can universal health care help overcome specific bottlenecks for TB diagnosis and care?

- What are the opportunities/challenges for linking health insurance programs to TB control objectives, including active case finding, integration of private providers (public-private mix), and expansion of MDR TB services, to achieve national TB control targets?

The interview guides are included in Appendix 2. A total of four interview guides were developed, relating to the categories below. In each country, an average of 10-12 interviews were conducted over a period of one to 
two weeks. The interview guides were tailored to ensure applicability to the country setting; however, the general meaning and purpose of the guides remained consistent. Interviews were conducted at the following levels:

- Policy/ program level: MOH/ NTP manager (1-2 total)

- Insurance mechanism: National Health Insurance Managers (1-2 total)

- Implementation level: District or Facility manager (3-5 in total)

- Community level: NGO, community health workers, DOTS supporters, or other

The findings from each country were compiled in detailed country-level reports and summarized in this synthesis report, which provides a framework for an analysis of the impact of insurance programs on TB healthseeking behavior and service delivery systems.

\section{Results}

The four countries highlighted in this assessment currently implement significantly different models for publicly-supported health insurance. Each country has continued to evolve its approach over time, to better target services to vulnerable population groups, improve the quality of services, and streamline administrative processes. In many ways, the models presented are not directly comparable; however, it is still important to identify the features which have contributed to successes or challenges in relation to contributions to TB control. The table below (Table 1) shows key findings from the four assessments on the role of national health insurance in the

Table 1. Key findings from four Country Assessments.

\begin{tabular}{|c|c|c|c|c|}
\hline & Thailand & Philippines & India & Peru \\
\hline Access to Services & $\begin{array}{l}\text { Better for Thai citizens with } \\
\text { 13-digit numbers but not for } \\
\text { migrants and Thais without } \\
\text { coverage; patients may not go } \\
\text { to hospital of choice }\end{array}$ & $\begin{array}{l}\text { Increase in number of accredited } \\
\text { TB DOTS facilities; limited avail- } \\
\text { ability of accredited providers }\end{array}$ & $\begin{array}{l}\text { More TB services available to } \\
\text { members of public sector em- } \\
\text { ployee insurance; insurance for } \\
\text { the poor only covers hospital- } \\
\text { ization for TB services }\end{array}$ & $\begin{array}{l}\text { Access to services in- } \\
\text { creased, less so for poor } \\
\text { and vulnerable popula- } \\
\text { tions }\end{array}$ \\
\hline Service Quality & $\begin{array}{l}\text { Improvements due to consis- } \\
\text { tency across TB Screening and } \\
\text { Treatment Guidelines }\end{array}$ & $\begin{array}{l}\text { Improvements due to accredita- } \\
\text { tion }\end{array}$ & Not assessed & $\begin{array}{l}\text { Community services weak } \\
\text { or limited }\end{array}$ \\
\hline Reimbursement & $\begin{array}{l}\text { Short period for reimburse- } \\
\text { ment to health providers }\end{array}$ & $\begin{array}{l}\text { Delayed reimbursement to DOTS } \\
\text { facilities is a key barrier/ disincen- } \\
\text { tive for pursuing accreditation }\end{array}$ & Not assessed & Not assessed \\
\hline $\begin{array}{l}\text { Additional Health } \\
\text { Service Require- } \\
\text { ments }\end{array}$ & $\begin{array}{l}\text { Increased administrative } \\
\text { responsibilities and capacity } \\
\text { building in monitoring and } \\
\text { evaluation, data management, } \\
\text { coordination }\end{array}$ & $\begin{array}{l}\text { Administration of claims; accred- } \\
\text { itation process; coordination; } \\
\text { accreditation; patient information }\end{array}$ & Not assessed & $\begin{array}{l}\text { Better coordination exists } \\
\text { between ESN-PCT and } \\
\text { MINSA; long wait time } \\
\text { required by EsSalud to }\end{array}$ \\
\hline $\begin{array}{l}\text { Health Seeking } \\
\text { Behaviors }\end{array}$ & $\begin{array}{l}\text { Some reluctance to seek early } \\
\text { diagnosis due to long wait } \\
\text { time at hospitals, transport } \\
\text { costs, loss of income, and fear } \\
\text { of disease }\end{array}$ & $\begin{array}{l}\text { Many persons seeking TB treat- } \\
\text { ment in private sector go to phar- } \\
\text { macies to reduce costs; Absence } \\
\text { of subsidy for TB patients for } \\
\text { transport may lower motivation }\end{array}$ & $\begin{array}{l}\text { Preference for private sector; } \\
\text { Absence of TB patient subsidy } \\
\text { for transport costs and loss of } \\
\text { wages may lower motivation }\end{array}$ & $\begin{array}{l}\text { Persistent registration } \\
\text { gaps for lower socioeco- } \\
\text { nomic levels; absence of } \\
\text { community services and } \\
\text { support }\end{array}$ \\
\hline Coverage & $\begin{array}{l}\text { No coverage for non-regis- } \\
\text { tered Thais and non-regis- } \\
\text { tered migrants }\end{array}$ & $\begin{array}{l}\text { Widespread coverage; targeted } \\
\text { towards vulnerable poor }\end{array}$ & $\begin{array}{l}\text { Public sector employees; Other } \\
\text { Insurance for low-income } \\
\text { populations only includes hos- } \\
\text { pitalization and not outpatient } \\
\text { services }\end{array}$ & $\begin{array}{l}\text { Equally available to all; } \\
\text { in practice, routinely not } \\
\text { accessed by poor and } \\
\text { vulnerable }\end{array}$ \\
\hline Coordination & $\begin{array}{l}\text { Strong coordination with NTP, } \\
\text { improved data sharing needed }\end{array}$ & $\begin{array}{l}\text { Coordination difficult among } \\
\text { diverse actors }\end{array}$ & $\begin{array}{l}\text { Limited collaboration with } \\
\text { RNTCP }\end{array}$ & $\begin{array}{l}\text { Stronger coordination } \\
\text { needed with ESN-PCT, } \\
\text { especially for health pro- } \\
\text { motion and outreach and } \\
\text { community level activities }\end{array}$ \\
\hline Financing & $\begin{array}{l}\text { Government finances TB } \\
\text { services for insurance plan } \\
\text { measures; Global Fund project } \\
\text { provides funding for services } \\
\text { for migrant TB patients and } \\
\text { some subsidies for other } \\
\text { indirect costs }\end{array}$ & $\begin{array}{l}\text { Government finances TB services } \\
\text { through PhilHealth; however, } 49 \\
\text { privately run TB DOTS centers } \\
\text { are either self- sustainable or can } \\
\text { access private funding }\end{array}$ & $\begin{array}{l}\text { RNTCP is being funded and } \\
\text { supported through the World } \\
\text { Bank loan, and the Global Fund } \\
\text { grants. }\end{array}$ & $\begin{array}{l}\text { Financing comes through } \\
\text { various Ministries and } \\
\text { coordinating bodies; par- } \\
\text { tial support from Global } \\
\text { Fund; monthly contri- } \\
\text { butions from workers/ } \\
\text { employees }\end{array}$ \\
\hline
\end{tabular}


provision of TB services. Access to TB services increased for registered members in Thailand and the Philippines ${ }^{4}$ when national insurance was introduced. In India, access improved for some beneficiaries of insurance - members of public sector employee coverage - but not for insurance members below the poverty line.

On the other hand, some characteristics of national health insurance can restrict access to provision of $\mathrm{TB}$ services. In Thailand, restrictions on the populations that are covered, location of facilities where services are offered, and increased waiting time may contribute to access barriers (although access and uptake is generally strong). In the Philippines, patients are obliged to seek out accredited sites, which may not be the most convenient, and populations that have not registered for at least three months are denied coverage. In India, insurance programs for the poor only cover hospitalization and do not include diagnosis and DOTS services.

Service quality improved with the introduction of national insurance in Thailand and the Philippines due to the introduction of standards for screening and treatment, and accreditation process (for the Philippines). However, the quality of services varied among facility levels in Thailand and provider capability is limited in the Philippines.

Changes in administrative and management responsibilities occurred with the adoption of national insurance in Thailand. Administrative responsibilities and data management shifted from the NTP to managers at the district and health facility levels, indicating that the impact of these additional time commitments should be considered in planning for the integration with national health insurance programs. The MINSA in Peru has maintained both a centralized and decentralized approach to TB management/support/supervision. The central NTP unit retains a key role in coordination with network-level supervisors that check quality and train local staff. The NTP is currently redesigning its national TB strategy to review how delivery and support services can be organized. Timely TB data (cohort) for decision making at the central level remains a challenge.

Timely reimbursement is a key motivator for service providers, as seen in studies of fee exemptions for the poor ${ }^{5}$. When program managers do not reimburse health facilities quickly, health providers are often de-motivated and are less likely to provide quality services to patients. While the reimbursement of TB service costs has been timely in Thailand, delayed reimbursement to DOTS has been a key barrier in the Philippines.

Indirect costs were also found to be an important deterrent to TB health-seeking behavior, even when primary costs for diagnosis and treatment are covered through the insurance mechanism. In all case studies, the indirect costs of seeking treatment - i.e., fares for transport, loss of wages, nutritional support needs - were reported to be a disincentive for treatment compliance or seeking care through designated facilities for treatment, particularly for vulnerable populations. In Peru, while much progress has been made in increasing the availability of services, the lack of adherence support and coverage for indirect costs was noted as a critical barrier to reaching the most vulnerable patients. This was tied to the need for stronger community-based services overall, especially in the context of improving service delivery for MDR-TB patients.

TB patients were reported in many settings to prefer to utilize private services, suggesting that service utilization could be improved if the private sector is included in national health insurance programs. In the Philippines, PhilHealth has included private sector providers in their program, though more is needed to increase the number of accredited private facilities and improve linkages with other providers such as pharmacists. In India, members of the BPL insurance programs seek care in alternately the RNTCP or the private sector, but there are insufficient referral mechanisms or linkages to allow adequate follow up as patients move between sites. In Thailand, the NHSO model focuses strongly on passive case finding approaches, which may contribute to delays in accessing care; in this case, mechanisms to encourage outreach and linkages with other care providers at the community level would be beneficial. In Peru, MINSA has comparably stronger community-level services than EsSalud, which relies on passive case finding. EsSalud has demonstrated flexibility in allowing members to use services from other networks, including MINSA and private insurance providers, and contracts out certain services it is not able to provide; this approach could be extended to the community level. Neither program in Peru has formal mechanisms for reaching out to other health providers, although pharmacies are a preferred provider for non-registered patients.

Health promotion and communication using mass media, campaigns, group presentations, and interpersonal communication are critical parts of informing the at-risk population regarding prevention and transmission of $\mathrm{TB}$, counseling $\mathrm{TB}$ patients during treatment regimen, and informing family members and other contacts of TB patients. Health promotion and communication activities also serve to engage health providers and managers, resulting in increased awareness of the risks and the value of integrating TB prevention and detection in day-to-day consultations and planning processes. In all the models examined, stronger efforts were needed to develop health promotion channels through the insurance mechanisms, linked to information on how and why patients should register and use in-service providers. Information and 
awareness campaigns were rarely targeted to close gaps in service provision to TB patients.

The health insurance models discussed in each country are primarily financed jointly through the governments and the Global Fund as well as premiums from users, although TB patients are typically paying for indirect costs - their transportation and other expenses. Gaps in coverage are often covered through Global Fund projects and NGOs. However, it should be noted that threats to the long-term availability of Global Fund resources may place increased pressure on governments to cover TB control costs.

\section{Discussion}

The four case studies demonstrate that integration of TB services with national health insurance can have a positive effect on access to services and their quality. On the other hand, each of the models assessed impose different types of restrictions which can limit the utilization of services. Some restrictions are planned and are part of the design of the insurance model. Others, however, are indirect or unintended consequences of implementation. As it relates to $\mathrm{TB}$, the findings of the assessment have highlighted the need to carefully examine the impact of restrictions in terms of access and use of TB services. In Thailand, the case study found that long wait times at facilities discouraged patients from obtaining services through the national health insurance. In the Philippines, the case study found that many patients perceive that they will have to pay direct and indirect costs for TB services in the public sector and prefer instead to seek treatment in the private sector, including pharmacies, to reduce costs.

The primary goal of publicly-supported health insurance programs is to improve access to care for a vulnerable segment of the population and, especially as it relates to TB, have the potential to play an important role in improving public health. However, specific objectives for health insurance programs are not typically defined in terms of disease objectives. In countries with significant burdens of key diseases like TB which threaten to jeopardize overall population health (as well as long term growth and development), specific considerations should be made to ensure that the NHI program is designed to be a driving force for controlling the epidemic. The decision to develop and adopt a publicly-supported insurance model should ideally form part of broader health systems reform efforts, and the design of the insurance model should, therefore, include features geared at reinforcing and advancing the country's health systems strengthening objectives.

An issue facing each country, in different degrees, is the separation between the functions of the NTP and the insurance planning and implementation agency. The addition of an insurance program, and possibly other agencies with financing or regulatory functions, adds another level of complexity in terms of planning, organizing, and delivering health services. A key overarching conclusion from the assessment is that strong coordination is needed between health policymakers and program managers to carefully design models for the integration of TB services under national health insurance. Careful planning is needed to ensure that all parties understand their roles and responsibilities within the systems and that health providers are motivated to provide high-quality TB services, and patients have incentives to utilize the services. A hypothetical coordination structure presented in Figure 3 outlines some of the "best practice" elements for collaboration between TB partners in an NHI

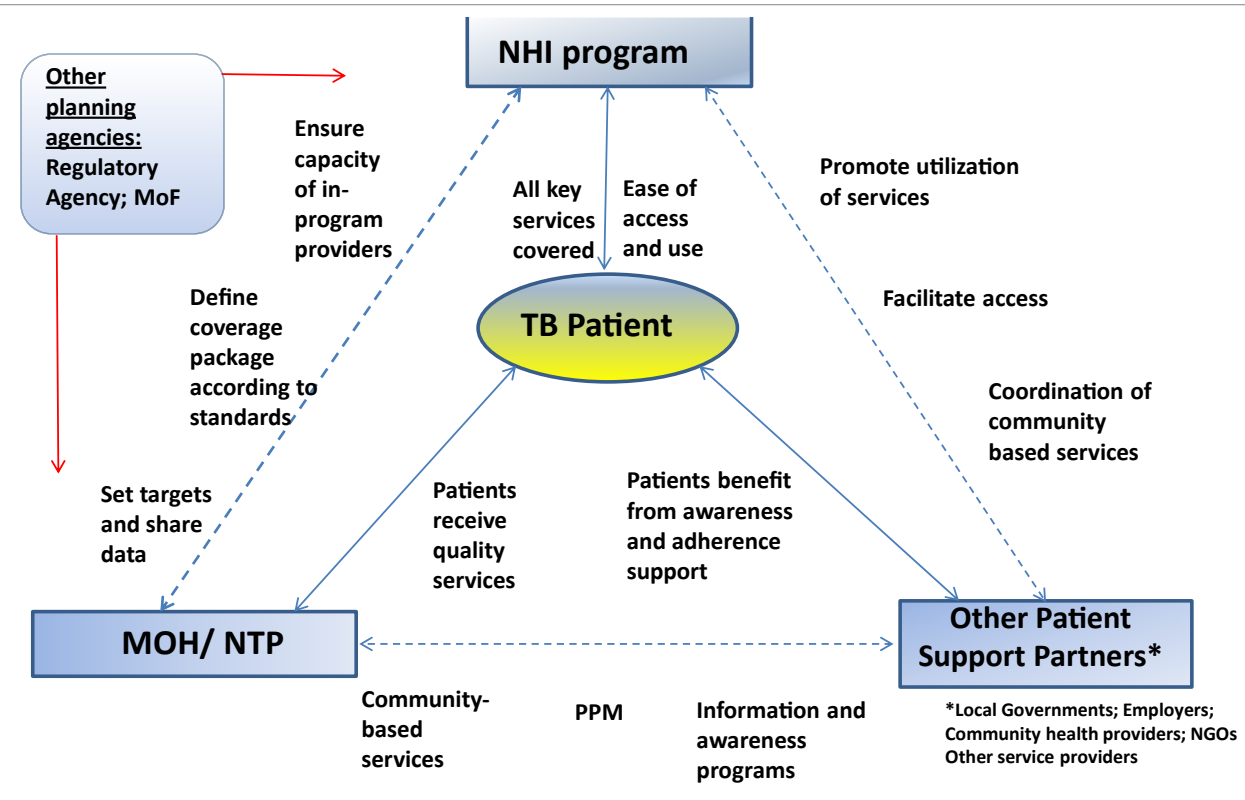

Figure 3. Lines of Coordination for Delivery of TB Services Under UHC. 
system identified in the assessments. This framework lays out potential roles for NTP, insurance program managers, and other relevant partners depending on the country (employers, NGOs, community partners) taking into consideration issues related to both demand and supply for TB services, including service quality, access to insurance benefits for vulnerable TB patients, and continuum of care for TB services.

There is a high degree of complexity involved in the implementation of a successful UHC system, and one of the outcomes of such an initiative, when implemented well, is to support improvements across the entire health system, rather than vertically building disease-specific programs. However, in countries with a significant burden of infectious diseases such as TB, it is important to demonstrate improvements in disease-specific outcomes, and the insurance program should ideally reinforce the adoption of standards for quality services and laboratory protocols, training curricula for diagnosis of TB, including MDR-TB strains, service delivery, and administration. To ensure that the supply of high-quality TB services is available, the following issues should be considered:

1. Clearly defined objectives for improving TB control should be articulated (i.e., as part of a TB National Strategic Plan), which reflect and reinforce broader health systems strengthening objectives. Standard operating procedures for TB diagnosis, DOTS, and inpatient services should be developed/updated so, there is clarity on how to deliver high-quality TB services. These targets and standards should be shared with the national health insurance planning and implementing body to ensure that they are incorporated to the best extent possible in the design of the insurance program (i.e., when defining and targeting key populations for coverage, when defining the benefits package, and when setting accreditation standards).

2. When national insurance programs integrate TB services into their programs, health providers may be given additional responsibilities for TB services in administration, monitoring and evaluation, and data management. In this case, it may be important that additional training is provided for the staff. In addition, the impact of additional administrative responsibilities on the time management of program managers at different levels of the health system should be evaluated.

3. Health providers should be reimbursed for claims in a timely manner to ensure that they are motivated to provide TB services and can maintain adequate infrastructure. If health providers are not reimbursed within a relatively short period, they will become discouraged and less likely to provide the service.

4. Health insurance plans often have gaps in coverage for services, especially for community-level treatment, support services, and MDR-TB services. The program managers should evaluate how to best mitigate these gaps in coverage for populations with a TB burden. Insurance programs should be encouraged to develop mechanisms for partnering with other TB providers, i.e. at the community level, to support a continuum of patient care.

5. Motivation to use TB-related insurance benefits will be increased by the inclusion of TB patient benefits to offset costs associated with travel and treatment at in-service facilities. Especially in cases where there are restrictions on service sites resulting in increased distances from a patient's home or work, the cost of transport is an important factor in where a patient decides to seek care. The development of structures to provide direct patient benefits or subsidies through an NHI program has not yet been implemented in the countries included in this assessment but presents an important avenue to explore as a means of increasing access and utilization of TB services as well as to support treatment adherence.

Countries planning to implement/revise national health insurance programs should also consider factors that affect the demand for TB services for patients. These deterrents include: 1) indirect costs of transport and loss of wages; 2) lengthy wait times for services; 3) stigma from being identified as a TB patient; 4) lack of choice of health facilities for TB services; and 5) lack of information on location and times to obtain services (as well as lack of information about TB in general). To ensure that all populations with a TB burden in a country are eligible and motivated to obtain services through NHI, the following issues should be considered:

1. What disincentives exist for health seeking for TB services at in-service providers such as lengthy wait times, long distances to health facilities offering services, and unexpected fees?

2. Are patients encountering stigma when they seek treatment at health facilities?

3. Are all key TB services covered through the insurance package or will the patient need to seek care from multiple service providers?

4. Do TB patients perceive that in-service providers have higher quality TB services and better accessibility than alternative (non-covered) providers?

5. Is information, education and communication (IEC) and social mobilization on the benefits of getting screened and treated for TB sufficient? Is this linked to information on how/ why a patient should access insurance benefits? 


\section{Recommendations}

Recommendations for designing/revising the integration of TB service into national health insurance are divided into the following sections: supply, demand, and financing.

\section{Supply-related recommendations:}

1. Health insurance programs that are integrated with TB services should adopt NTP standard operating procedures for diagnosis, DOTs and treatment, monitoring and evaluation, laboratory analysis, and data management. They should also develop checklists and other tools to facilitate the supervision of these services. The insurance program should develop routine mechanisms for collaboration with the NTP to review the implementation of services against standards.

2. Program managers should ensure that health providers with TB services are reimbursed in a timely fashion. When designing reimbursement payments for health providers of TB services, program managers should include costs of administration, monitoring and evaluation, and data management as well as diagnosis and treatment. The NTP or NHI should also commission a cost study to determine the appropriate reimbursement of health facilities and/or providers by the NHI.

3. Training programs should be designed so that health providers are able to perform their new responsibilities under the program, including administration, monitoring and evaluation, and data management. Structures for integrating on-going capacity building and mentoring, possibly tied to accreditation mechanisms if appropriate, should be explored to support the integration of TB within high volume and problem-prone services in HBC NHIs to reduce missed opportunities.

4. Conduct an assessment of additional administrative responsibilities required to integrate $\mathrm{TB}$ diagnosis and services at different levels of the health system to determine training needs and personnel time requirements.

5. If possible, national health insurance programs should include coverage for all TB services, i.e. diagnosis, consultation, DOTS, and inpatient services. If the health insurance is unable to provide all the services, insurance managers should collaborate with the NTP to ensure the implementation of a strong referral system to ensure detection of TB cases.

6. MDR-TB is a growing concern in many TB high-burden countries. As cases of MDR-TB increase, there is a need for countries to examine their systems for scaling up access to MDR-TB diagnosis, treatment, and support services. Currently, MDR-TB treatment is most often offered at limited sites directly supported by the NTP; there is a need to explore models for expanding decentralized service provision (i.e., in tandem with efforts to introduce community programmatic management of MDR-TB) and to increase the role that NHI programs can play especially in supporting referrals, ambulatory treatment phases, and patient adherence.

7. The insurance program should coordinate with the NTP (and other programs including the national HIV/ AIDS program) to map service needs against the known vulnerable or at-risk populations. Service coverage should be designed to target evidence-based gaps in TB services.

8. National health insurance managers should try to incorporate private sector facilities into NHI programs through accreditation or other mechanisms to improve access and coverage levels.

\section{Demand-related recommendations:}

Patient factor delays or barriers to service utilization can stem from social/community factors (knowledge and perceptions of the disease), health system-related factors (barriers such as provider attitudes, which may be similarly present in most health facilities, whether or not they are supported by an insurance program) and factors resulting from the design of the insurance model (i.e., lack of accredited sites or overburdening/ long wait times). A survey of patients should be conducted to evaluate where disincentives for TB service utilization occur and why the NHI should work with the MOH/ NTP to implement some possible solutions to the issues that were identified.

In recent years, a growing emphasis has been placed on moving towards an active case finding approach to close the gap between the number of patients with active TB disease and those who are identified and put on effective treatment. This approach includes several interventions including increased screening for TB for patients who present with other related infections or as part of routine health services, tracing and following up contacts of TB patients, and more active household or community outreach to identify suspected TB cases. A current challenge in this regard is the passive approach utilized by many insurance programs to enroll patients. Many of the NHI programs assessed did not have formal mechanisms for coordinating with communities or community-based TB services or linking with health promotion efforts.

1. Patient and health system barriers to care: Issues related to identifying and overcoming patient and health system barriers to TB services may fall outside of the direct mandate of an insurance program (i.e., 
population-based information campaigns to raise awareness on TB). However, many functions can be incorporated within the implementation of the insurance program to reinforce and support these efforts (i.e., mechanisms to inform and educate members about the plan and coverage can also carry information on TB services and the need to seek care). Insurance managers and NTPs should adopt routine mechanisms for identifying and exploiting insurance systems for targeting improvements to patient access to services.

2. Specific barriers to care resulting from the design of the insurance program should be targeted by adopting measures such as i) incorporating patient satisfaction and feedback mechanisms; ii) monitoring numbers of TB patients served and setting targets against estimated number of cases; and iii) identifying areas with high TB prevalence and targeting improvements in access to TB services in these areas (i.e., streamline accreditation of DOTS centers in these locations).

3. Attempt to provide a choice of facilities to TB patients or provide other incentives for patients to use the assigned facilities.

4. The program managers should provide at least partial subsidies for transport and wage loss compensation for low-income TB and MDR-TB patients to improve treatment compliance. Insurance programs should actively pursue partnerships with community providers and treatment support organizations in order to provide patients with information and referrals to other support mechanisms.

5. NHI should assist in the design of an IEC/social mobilization campaign to publicize the benefits of getting diagnosed and treated for TB patients and information on locations and times to obtain services, in coordination with other TB partners including community partners, advocates, employers, and the NTP.

\section{Financing-related recommendation:}

1. Over the medium- and long-term, managers of national health insurance in high burden countries need to develop plans to take over the financing of these services to ensure that TB diagnosis and treatment services are continuous.

\section{Public and patient education}

1. TB-specific marketing channels should be explored, targeting information on how to use the insurance service package to high-risk TB populations, and linking messages regarding utilization of TB services to health promotion messages designed to raise community awareness of TB disease. Coordination should be sought between local government units, communitybased TB partners, NGOs, and others who are providing $\mathrm{TB}$ related information at the community level to integrate information on how patients may access and use insurance benefits.

\section{Metrics and Measurement}

1. Strengthening capacities to demonstrate improvements in disease-specific outcomes as a result of an NHI program could have a significant effect on increasing utilization rates. Stronger coordination between the NHI program and the MOH/NTP to track and share TB data has the potential to reinforce patient information programs regarding the benefits of accessing insurance membership, as well as further increasing the funding pool to support service provision as additional members seek services. Improving data tracking and sharing for TB indicators will also assist the insurance program and the $\mathrm{MOH} / \mathrm{NTP}$ to promote improved planning for delivery of TB services, training of service providers, and to identify necessary changes in the benefits package.

\section{Framework for Cost Analyses of TB Service Integration in Health Insurance Programs}

This framework outlines the costs associated with the integration of tuberculosis services into health insurance programs. Some assumptions made in this framework are the following: 1) TB service coverage can be increased through integration into national health insurance if access to services improves, especially for vulnerable populations; and 2) more patients would utilize TB services if the insurance covers some of the costs to the patients as well as service costs. The sections below are designed to assist insurance planners and $\mathrm{MOH} / \mathrm{NTP}$ decision-makers to evaluate the potential for expansion of TB services covered under the insurance model (either the package of services covered or the scope of coverage to key population groups).

When calculating costs, the planner must decide if they would like to calculate incremental or total costs of introducing TB services. If $\mathrm{s} / \mathrm{he}$ is conducting a costeffectiveness or cost-benefit analysis of integration with national health insurance, an incremental cost analysis should be done. That is, if integration is being compared to no integration, it is preferable to use incremental costing. The advantage of this type of costing is that the increase in the value of resources for integration over other scenarios can be calculated and compared.

If the planner/researcher is doing a cost analysis to evaluate the costs of integration for planning purposes, s/ he may instead want to conduct a total cost analysis. This type of costing will allow the planners to estimate the value 
of all resources that will be employed for integration with TB services. Shared costs, or the proportion of resources that are shared with other resources, are estimated as part of total costs. For example, shared costs include the value of health personnel time or building space.

The planner then needs to decide which resources are likely to be covered under insurance and which have other sources of financing (e.g., TB patient). This information will determine which data need to be collected from different sources for the cost analysis. Also, the calculation of some costs may not be required, depending on the objective of the analysis. If the salary costs of health workers are covered by the government and not through the insurance, then the calculation of the value of personnel time may not be needed for the analysis. The calculation of patient costs will be necessary if these are likely to be reimbursed or analyzed for their impact on compliance to treatment.

Both financial and economic costs are calculated for cost analyses. If the researchers are only interested in estimating or projecting the financial outlay needed by the Ministry of Health to integrate TB services with national health insurance, then they may prefer to use the financial cost calculation. Financial costs are the value of resources to the payer and would include the value of actual resources used for the integration. This type of analysis is useful in assessing the affordability of TB service integration with $\mathrm{NHI}$ to the government. This analysis would not require the calculation of the value of donated goods and services such as MDR-TB drugs.
Economic costs comprise the value of all outlays for the integration that has been paid for by the $\mathrm{MOH}$ or other sources of financing and includes the value of all goods and services that have been donated. For instance, the full value of subsidized or donated MDR-TB drugs, the value of a health worker and volunteer labor would be included in the cost estimates. Such an analysis gives a complete picture of all the resources that are tied up in TB service integration with NHI and captures their opportunity cost. Economic costs are used in cost-effectiveness and cost-benefit analysis. Economic costs may be used by governments and donors to evaluate sources of financing for introduction, as well as for evaluating program sustainability and health system requirements.

The impact of integration of TB services into insurance on service costs can be divided into four components: 1) diagnosis, 2) treatment, 3) DOT/Follow-up, and 4) social support (see Table 2).

\section{Acknowledgments}

URC would like to acknowledge the assistance of our partners in India, Peru, Thailand, and the Philippines. This assessment has been conducted under USAID TB CARE II 2010-2020. URC is grateful to the field teams who prepared the assessment report ${ }^{6,7}$, including Alisha Smith-Arthur, Neeraj Kak and Refiloe Matji and those who undertook data collection in each country, including Paul Richardson, Graciela Meza Sanchez, Gani Perla, Teresa AlhambraBarzaga, Darin Kongkasuriyachai, Gautam Chakraborty,

Table 2. Impact of TB Service Integration with Insurance on Service and Patient Costs.

\begin{tabular}{|c|c|c|c|}
\hline TB Service & Cost Components & Impact of Insurance on Service Costs & $\begin{array}{l}\text { Impact of Insurance on Patient } \\
\text { Costs }\end{array}$ \\
\hline $\begin{array}{l}\text { Diagnosis } \\
\text { Sputum Microscopy } \\
\text { Chest X-Ray } \\
\text { Culture/sensitivity }\end{array}$ & $\begin{array}{l}\text { Service: Health worker time for } \\
\text { diagnostic time and for registration, } \\
\text { laboratory worker time, specimen } \\
\text { collection supplies, laboratory supplies, } \\
\text { laboratory equipment and running } \\
\text { costs, stationery, supervision } \\
\text { Patient: charges for diagnostic tests, } \\
\text { transport, loss of wages, other (e.g. } \\
\text { food) }\end{array}$ & $\begin{array}{l}\text { - Test already offered for free in most } \\
\text { countries } \\
\uparrow \text { in services if NHI covers patient } \\
\text { charges for X-Rays } \\
\uparrow \text { in services if NHI covers patient } \\
\text { charges for culture/sensitivity tests }\end{array}$ & $\begin{array}{l}\text { - No change for transport and loss } \\
\text { of wages unless insurance provides } \\
\text { a subsidy to TB patients. } \\
\downarrow \text { if NHI covers patient charges for } \\
\text { X-Rays } \\
\downarrow \text { if NHI covers patient charges for } \\
\text { culture/ sensitivity tests }\end{array}$ \\
\hline $\begin{array}{l}\text { Treatment } \\
\text { First line drugs } \\
\text { Second-line or MDR- } \\
\text { TB drugs } \\
\text { Inpatient Care }\end{array}$ & $\begin{array}{l}\text { Service: Health worker time, drugs, } \\
\text { supplies for recordkeeping, cost of bed } \\
\text { time in hospital (for inpatient care), } \\
\text { supervision } \\
\text { Patient: transport, loss of wages, other } \\
\text { (e.g. food) }\end{array}$ & $\begin{array}{l}\text { - first-line drugs usually provided free } \\
\text { of charge } \\
\text {-+ impact unclear for second-line drugs } \\
\text { since depends on whether drugs are } \\
\text { routinely available and reimbursable }\end{array}$ & $\begin{array}{l}\text { - no impact for first-line drugs since } \\
\text { already covered in most countries } \\
\downarrow \text { cost of second-line drugs if cov- } \\
\text { ered by insurance } \\
-\uparrow \text { could increase if MDR TB drugs } \\
\text { are only given out at certain hospitals }\end{array}$ \\
\hline DOT/Follow-up & $\begin{array}{l}\text { Service: Health worker time, supplies } \\
\text { for recordkeeping } \\
\text { Patient: transport, loss of wages, other } \\
\text { (e.g. food) }\end{array}$ & $\begin{array}{l}\text { 个Increase in number of services pro- } \\
\text { vided if case detection improves }\end{array}$ & - already covered \\
\hline Social Support & $\begin{array}{l}\text { Service: Health worker or communi- } \\
\text { ty agent time, food or other type of } \\
\text { support } \\
\text { Patient: transport, loss of wages, other } \\
\text { (e.g. food) }\end{array}$ & $\begin{array}{l}\uparrow \text { costs for nutritional and other types } \\
\text { of support }\end{array}$ & $\begin{array}{l}\downarrow \text { costs to patient if nutritional sup- } \\
\text { port and other assistance given }\end{array}$ \\
\hline
\end{tabular}


and Tushar C. Mokashi, who assisted to develop case study reports for each country. URC further appreciates the support and assistance of the USAID country missions who helped advance the project.

TB CARE II is funded by United States Agency for International Development (USAID) under Cooperative Agreement Number AID-OAA-A-10-00021. The project is implemented by the prime recipient, University Research Co., LLC (URC), and sub-recipient organizations.

\section{References}

1. World Health Organization Health Financing for Universal Coverage, 2012. http://www.who.int/health_financing/universal_coverage_ definition/en/index.html
2. World Health Organization, Health Systems Financing: The Path to Universal Coverage, The World Health Report 2010.

3. O'Connell T. National Health Insurance in Asia and Africa. UNICEF. 2012.

4. LimN. "'Conservative' and 'sluggish' PhilHealth misses healthcare target" GMA News, April 20, 2011. Accessed July 26, 2012. http:// www.gmanetwork.com/news/story/218278/news/nation/ conservative-and-sluggish-philhealth-misses-healthcare-target.

5. Bitran R, Giedion U. Waivers and Exemptions for Health Services in Developing Countries. Social Protection Unit Human Development Network the World Bank. 2003.

6. Synthesis Report: Inclusion of TB in National Insurance Programs. United States Agency for International Development (USAID) TB CARE II Project. 2013.

7. Strengthening Coverage for TB through Universal Health Care. United States Agency for International Development (USAID) TB CARE II Project. 2013. 